\title{
Obstetrik ve Jinekolojik Operasyonlarda Cerrahi Alan Enfeksiyonları İle İlgili Risk Faktörlerinin Dğerlendirilmesi
}

\section{Evaluation of Risk Factors Related to Surgical Site Infections in Obstetric and Gynecologic Operations}

\author{
${ }^{1}$ Hilal USLU YUVACI, ${ }^{1}$ Mehmet Musa ASLAN, ${ }^{2}$ Elif KÖSE, ${ }^{1}$ Merve KESKIN PAKER, \\ ${ }^{1}$ Arif Serhan CEVRIOĞLU
}

\author{
${ }^{1}$ Sakarya Üniversitesi Tıp Fakültesi Kadın Hastalıkları ve Doğum AD, Sakarya \\ ${ }^{2}$ Sakarya Üniversitesi Tıp Fakültesi Halk Sağlığı AD, Sakarya
}

Hilal Uslu Yuvac1: https://orcid.org/0000-0001-8067-3165

Mehmet Musa Aslan: https://orcid.org/0000-0002-7830-5002 Elif Köse: https://orcid.org/0000-0002-2232-4538

Merve Keskin Paker: https://orcid.org/0000-0003-4796-0909

Arif Serhan Cevrioğlu: https://orcid.org/0000-0002-3810-6519

\section{ÖZ}

Amaç: Cerrahi alan enfeksiyonları, cerrahi sonrası 30 gün içerisinde insizyon yerinde ortaya çıkan enfeksiyonlardır. Jinekolojik cerrahi sonrası en sık görülen komplikasyon cerrahi alan enfeksiyonudur. Cerrahi alan enfeksiyonlarının gelişmesinde risk faktörleri değiştirilebilir ve değiştirilemez faktörler olarak ikiye ayrılır. Değiştirilebilir risk faktörleri arasında preoperatif anemi, diyabetes mellitus, hipertansiyon, malnütrisyon, sigara kullanımı; değiştirilemeyen risk faktörleri arasında yaş, obezite, malignite gibi faktörler bulunmaktadır. Bu çalışmada jinekolojik ve obstetrik cerrahi sonrası cerrahi alan enfeksiyonu gelişen olgularda risk faktörleri değerlendirildi.

Materyal ve Metot: Retrospektif olgu-kontrol çalışmasında Ocak-Aralık 2017 yılı içerisinde jinekolojik ve obstetrik cerrahi geçirmiş; operasyon sonrası cerrahi alan enfeksiyonu gelişen 65 ve enfeksiyon gelişmeyen 52 hastanın demografik (yaş, kilo, beden kitle indeksi, kronik hastalık varlığı), preoperatif dönemde transfüzyon geçmişi, sigara kullanımı, tıbbi ve operasyon verileri karşılaştırıldı.

Bulgular: Cerrahi alan enfeksiyonu geçiren olguların yaş ve beden kitle indeksi enfeksiyon gelişmeyen olgulara göre daha fazla bulundu. Cerrahi alan enfeksiyonu gelişenlerde diyabet, hipertansiyon, malignite daha fazla oranda mevcuttu.

Sonuç: Cerrahi alan enfeksiyonları hasta morbiditesini artırmaktadır. Risk faktörleri arasında yaş, obezite, malignite, diyabet, hipertansiyon gibi faktörler bulunmaktadır. Risk faktörlerinin cerrahi öncesi belirlenmesi ve cerrahi alan enfeksiyonunu önlemeye yönelik tedbirler alınması önemlidir. Anahtar Kelimeler: Cerrahi alan enfeksiyonu, jinekolojik operasyon, obstetrik operasyon

\section{ABSTRACT}

Objective: Surgical site infections(SSI) are those that occur at the incision site within 30 days after surgery. They are the most common complications after gynecological surgery. For the development of SSI, risk factors are divided into two as modifiable and nonmodifiable factors. Modifiable risk factors include preoperative anemia, diabetes mellitus, hypertension, malnutrition and smoking, whereas non-modifiable risk factors include age, obesity, malignancy, etc. This study evaluated the risk factors in patients who developed SSI after gynecological-obstetric surgery.

Materials and Methods: This retrospective case-control study compared data including age, weight, body mass index(BMI) and presence of a chronic disease, history of preoperative transfusion, smoking and medical-operative data between 65 patients who underwent surgery and developed postoperative SSI and 52 patients who did not develop SSI from January to December 2017.

Results: Patients with SSI had higher age, weight and BMI than those without infection. The incidence of diabetes, hypertension and malignancy was higher in patients with SSI.

Conclusion: Surgical site infections increase morbidity rates. Risk factors for SSI include age, obesity, malignancy, diabetes and hypertension. It is important to determine the risk factors before surgery and to take precautions to prevent SSI.

Keywords: Gynecological surgery, surgical site infection, obstetric surgery
Sorumlu Yazar / Corresponding Author:

Hilal USLU YUVACI

Adres: Sakarya Üniversitesi Eğitim Araştırma Hastanesi Kadın

Hastalıkları ve Doğum AD., Ormanpark yanı, Merkez kampüs, 3.

Kat, 54100, Sakarya

Cep telefonu:05056236937

E-mail: hilaly@sakarya.edu.tr

Atıf/ Cited: Uluşen ve ark. Obstetrik ve Jinekolojik Operasyonlarda Cerrahi Alan Enfeksiyonları İle İlgili Risk Faktörlerinin Dğerlendirilmesi. Online Türk Sağllk Bilimleri Dergisi 2020;5(1):41-48. doi: 10.26453/otjhs.600815

\section{Yayın Bilgisi / Article Info:}

Gönderi Tarihi/ Received: 02.08.2019

Kabul Tarihi/ Accepted: 26.11.2019

Online Yayın Tarihi/ Published: 31/03/2020 


\section{GíRIS}

Cerrahi alan enfeksiyonları, cerrahi sonrası 30 gün içerisinde insizyon yerinde ortaya çıkan yüzeyel, derin ve cerrahi sırasında manipüle edilen veya kavitesi açılan organlarda ortaya çıkan enfeksiyonlardır. ${ }^{1}$ Postoperatif hasta morbiditesini artıran önemli bir sorundur. Jinekolojik cerrahiler sonras1 en sık görülen komplikasyon cerrahi alan enfeksiyonudur. ${ }^{2}$ Histerektomi sonrası \% 2,7 oranında cerrahi alan enfeksiyonu geliştiği gösterilmiştir. ${ }^{3}$

Cerrahi alan enfeksiyonlarının gelişmesinde; preoperatif anemi, diyabetes mellitus, hipertansiyon, malnütrisyon, sigara kullanımı gibi değiştirilebilir faktörler ve yaş, obezite, malignite gibi değiştirilemez faktörler bulunmaktadır. ${ }^{4-6}$

Özellikle önlenebilir faktörlerin operasyon öncesi düzeltilmesi konusunda ciddi çalışmalar yapılmaktadir. Diyabeti olan hastalarda glikoz seviyesinin regülasyonu, hipertansiyon kontrolü, profilaktik antibiyotik kullanımı, intraoperatif dönemde doku oksijenasyonunun ve normoterminin sağlanmasının cerrahi alan enfeksiyonlarını azalttığı gösterilmiştir. $^{7,8}$ Obez hastalarda cerrahi alan enfeksiyonunun önlenmesinde, cilt altı dokuda ölü boşluk bırakılmaması, gerekli ise cilt altı negatif basınçlı dren kullanımı önerilmektedir. ${ }^{9-13}$

Preoperatif dönemde düzeltilmesi gereken bir risk faktörü varsa düzeltilmesi, intraoperatif dönemde uygun cerrahi tekniğin kullanılması faydalı olabilir. $\mathrm{Bu}$ nedenle hastanın cerrahi öncesinde, cerrahi alan enfeksiyonlarının önlenebilmesi için risk faktörlerinin değerlendirilmesi gerekmektedir.

$\mathrm{Bu}$ çalışmada jinekolojik ve obstetrik cerrahi sonrası cerrahi alan enfeksiyonu gelişen olgularda risk faktörleri değerlendirildi.

\section{MATERYAL VE METOT}

Çalı̧̧ma için Sakarya Üniversitesi Tıp Fakültesi Girişimsel Olmayan Etik Kurulu'ndan etik onayı alındı (Tarih: 18.04.2018: Say1 71522473/050.01.04/105E.5743). Retrospektif olgu-kontrol çalışmasında, 1 Ocak-31 Aralık 2017 tarihleri arasında kadın hastalıkları ve doğum kliniğinde jinekolojik ve obstetrik nedenlerle operasyon yapilan hastalardan cerrahi alan enfeksiyonu tanısı ile hospitalize edilen tüm olgular $(n=65)$ çalışmaya dahil edildi. Olguların tıbbi bilgilerine hasta kayıtlarından ulaşıldı. Cerrahi alan enfeksiyonunu ameliyattan sonraki 30 gün içinde Hastalık Kontrol ve Önleme Merkezi(CDC) kriterlerine göre yüzeysel, derin veya organlarda meydana gelen enfeksiyon olarak tanımladık. ${ }^{1}$
Laparatomi ve vajinal cerrahi geçiren olgular çalışmaya dahil edildi. Operasyon sonrası cerrahi alan enfeksiyonu gelişen hastalarla aynı günde benzer operasyon yapilan hastalardan cerrahi alan enfeksiyonu gelişmeyenler $(\mathrm{n}=52)$ hastane kayıtlarından seçilerek kontrol grubu oluşturuldu. Grupların demografik özellikleri (yaş, kilo, beden kitle indeksi (BKİ), kronik hastalık varlığı), preoperatif dönemde transfüzyon geçmişi, sigara kullanımı, tıbbi ve operasyon verileri karşılaştırıldı. Bütün hastalar rutin olarak cerrahi öncesi 1 saat içinde 2 gr sefazolin intravenöz yoldan tek doz aldı, $120 \mathrm{~kg}$ üzerindeki hastaya $3 \mathrm{gr}$ sefazol uygulandı. Sürekli değişkenler ortalama \pm standart sapma ya da medyan (minimum:maksimum) değerleriyle ifade edildi. Kategorik değişkenler ise $\mathrm{n}(\%)$ ile ifade edildi. Kategorik değişkenlerin gruplar arasında yapılan karşılaştırmalarında ki-kare testi kullanıldı. Sürekli değişkenlerin gruplar arasında yapılan karşılaştırmalarında bağımsız T testi kullanıldı. İstatistiksel analizler için SPSS (IBM Corp. Released 2012. IBM SPSS Statistics for Windows, Version 21.0. Armonk, NY: IBM Corp.) programı kullanıldı. $\mathrm{p}<0.05$ değeri istatistiksel olarak anlamlı kabul edildi.

\section{BULGULAR}

Araştırmaya dahil edilen 117 hastanın \% 40,2'sinde hipertansiyon, \%28,2'sinde diyabetes mellitus, \% 12,8 'sinde eşlik eden malignite mevcuttu, $\% 16,2$ 'si sigara kullanıyordu. En sik uygulanan cerrahi total abdominal histerektomi idi. En sık insizyon şekli pfannestiel insizyondu. Cerrahi alan enfeksiyon gelişen hastaların ortalama hospitalizasyon süresi $7,21 \pm 7,24$ gündür. Olguların operasyon bilgileri Tablo 1' de verildi.

Cerrahi alan enfeksiyonları en sik birinci haftada ortaya çıktı. Yara yeri dehisensi nedeniyle, cerrahi alan enfeksiyonu gelişen olguların \% 87,7'sine sekonder sütür konuldu. Hastaların 10' una $(\% 8,5)$ vakum yardımlı kapatma kullanıldı. Olguların enfeksiyona ait bilgileri Tablo 2' de verildi.

Cerrahi alan enfeksiyonu geçiren olguların yaş ve BKİ enfeksiyon gelişmeyen olgulara göre daha fazla bulundu (sirasiyla $p=0,003, p<0,001, p<0,001$ ). Cerrahi alan enfeksiyonu gelişenlerde diyabet, hipertansiyon, malignite daha fazla oranda mevcuttu (sirasiyla $\mathrm{p}=0,006, \mathrm{p}=0,009, \mathrm{p}=0,041$ ) (Tablo 3).

\section{TARTIŞMA VE SONUÇ}

$\mathrm{Bu}$ çalışmada cerrahi alan enfeksiyonu geçiren olgu- 
ların yaş, BKİ ve diyabet, hipertansiyon, malignite gibi ek medikal hastalıkların olma durumu enfeksiyon gelişmeyen olgulara göre daha fazla bulundu.

Jinekolojik operasyonlardan sonra postoperatif komplikasyonların ortaya çıkması ile ilişkili olarak yaşın dikkate alınması önemlidir. Cerrahi alan enfeksiyonu oluşmasında ileri yaşın önemli bir risk faktörü olduğu bilinmektedir. ${ }^{14,15} \mathrm{Bu}$ çalışmada da literatüre uyumlu olarak jinekolojik operasyon sonrası cerrahi alan enfeksiyonu geçirenlerin, enfeksiyon gelişmeyenlere oranla daha yaşlı olduğu bulundu.

Değiştirilemeyen faktörler arasında yer alan obezitenin de, azalmış doku oksijenasyonu, dokularda azalmış antibiyotik penetrasyonu, azalmış immün fonksiyon ve suboptimal metabolik fonksiyon nedeniyle cerrahi alan enfeksiyonunu kolaylaştırdığı iddia edilmektedir. ${ }^{16-18}$ Ayrica obez hastalarda cerrahi alanın görülmesinin zor olmasına bağlı olarak cilt altı yağ dokuda daha fazla travma oluşturacak şekilde ekartasyonun ve uzamış operasyon süresinin de cerrahi alan enfeksiyonu oluşmasına katkı sağladığını düşünenler vardır. ${ }^{19}$ Ciltaltı yağ dokusu kalın olan vakalarda cilt altı yağ dokusunun potansiyel boşluk kalmayacak şekilde kapatılmasının, gerekli olursa cilt altına negatif basınçlı dren konulmasının enfeksiyon gelişme ihtimalini azaltacağı düşünülmektedir. ${ }^{19,20}$ Cilt altında boşluk kalması durumunda boşlukta seroma oluşacağını, seromanın enfeksiyon gelişmesini kolaylaştırdığını savunanlar vardır. ${ }^{9} \mathrm{Bi}$ zim çalışmamızda da literatüre benzer şekilde, cerrahi alan enfeksiyonu gelişen olguların, enfeksiyon olmayan olgulara göre daha kilolu olduğu bulundu. $\mathrm{Bu}$ çalışmada $10(\% 8,5)$ olguya vakum yardımlı kapatma kullanıldı.

Cerrahi alan enfeksiyonu için Diyabetes mellitus ve hipertansiyon gibi hastalıklar değiştirilebilir risk faktörleri arasında yer almaktadır. ${ }^{21,22}$ Diyabetik hastalarda kötü nutrisyonel durum, dokulara azalmış oksijen desteği, kötü glisemik kontrol ve artmış metabolik düzensizliklerin insizyon bölgesinin iyileşmesini bozduğu ve enfeksiyona zemin hazırladığı düşünülmektedir. ${ }^{7} \mathrm{Bu}$ nedenle diyabetik hastalarda kan şekerinin kontrolü cerrahi öncesi ve sonrası cerrahi alan enfeksiyonunu önlemek açısından önemlidir. Literatürle uyumlu olarak bu çalışmada enfeksiyon gelişen olgularda diyabetin eşlik etme oranı, enfeksiyon gelişmeyenlere göre fazla bulundu.

Jinekolojik malignite cerrahileri cerrahi alan enfeksiyonu açısından, benign nedenlerle yapılan cerrahile- re oranla daha risklidir. ${ }^{23}$ Kanser olgularında bozulmuş immünitenin cerrahi alan enfeksiyonu gelişimini kolaylaştırdığı düşünülmektedir. ${ }^{23}$ Ayrıca etkili olan diğer faktörlerde malignite cerrahilerinin, benign nedenlerle yapilan cerrahilere oranla daha geniş alanı kapsaması ve operasyon süresinin uzamasıdır. ${ }^{24} \mathrm{Bu}$ çalışmada literatürle uyumlu olarak cerrahi alan enfeksiyonu gelişen olgularda jinekolojik malignite cerrahisi uygulananların oranı daha fazla bulundu.

Hastanede kalış süresi cerrahi alan enfeksiyonlarına bağlı olarak uzamakta morbidite ve sağlık harcamalarında artışa yol açmaktadır. ${ }^{19,25}$ Bizim çalışmamızda da cerrahi alan enfeksiyonu gelişen hastaların ortalama 7,21 $\pm 7,24$ gün daha uzun süre hospitalize edildiği bulunmuştur.

Preoperatif anemi ve kan transfüzyonu gereksiniminin de cerrrahi alan enfeksiyonlarına yatkınlığı arttırdığı, perioperatif transfüzyonun cerrahi alan enfeksiyonu gelişimi ile anlamlı olarak ilişkili olduğu bulunmuştur. ${ }^{19}$ Bizim çalışmamızda preoperatif transfüzyonun cerrahi alan enfeksiyonu ile ilişkisi istatistiksel olarak anlamlı bulunmamıştır ( $\mathrm{p}>0,05)$. Bu çalışmanın preoperatif dönemde anemi düzeyini, transfüzyon miktarını göstermede kısıtlllığı nedeniyle iyi planlanmış geniş çaplı prospektif çalışmalara ihtiyaç vardır.

Çalışmanın retrospektif yapısı nedeniyle olguların preoperatif dönemdeki, anemi ve nutrisyonel durumu, tansiyon değerleri, glisemik kontrolü, operasyon süresi, sosyoekonomik düzeylerini bilmememiz çaıışmanın limitasyonudur.

Sonuç olarak; Cerrahi alan enfeksiyonları jinekolojik ve obstetrik cerrahilerden sonra en sık gelişen komplikasyonlardandır. Cerrahi alan enfeksiyonları için risk faktörleri arasında yaş, obezite, malignite, diyabet, hipertansiyon gibi faktörler bulunmaktadır. Bu enfeksiyonların önlenmesi hasta morbiditesini ve sağlık giderlerini azaltmak açısından önemlidir. Bu amaçla risk faktörlerinin cerrahi öncesi belirlenmesi, operasyonun planlanmasında ve cerrahi alan enfeksiyonunu önlemeye yönelik tedbirler alınmasında önemlidir.

Etik Komite Onayı: Çalışma için Sakarya Üniversitesi Tıp Fakültesi Girişimsel olmayan klinik araştırmalar etik kurulundan etik onayı alındı (Tarih: 18.04.2018: Say1 71522473/050.01.04/105-E.5743).

Çıkar Çatış̧ası: Yazarlar çıkar çatışması bildirmemişlerdir. 
Yazar Katkıları: Fikir - HUY ; Denetleme - ASC; Malzemeler - MMA, MKP; Veri toplanması ve/ veya işlemesi - HUY, MKP, EK; Analiz ve/veya yorum - HUY, MMA ; Yazıyı yazan - HUY, MMA. Hakem değerlendirmesi: Dış bağımsız.

Ethics Committee Approval: Our study was approved by the Sakarya University Ethics Committee of non-interventional clinical researches. ( D a t e : $\quad 18.04 .2018$ : Number: 71522473/050.01.04/105-E.5743)

Conflict of Interest: No conflict of interest was declared by the authors.

Author Contributions: Concept - HUY; Supervision - ASC; Materials - MMA, MKP; Data Collection and/or Processing - HUY, MKP, EK; Analysis and/ or Interpretation - HUY, MMA; Writing - HUY, MMA

Peer-review: Externally peer-reviewed.

\section{KAYNAKLAR}

1. Horan TC, Gaynes RP, Martone WJ, Jarvis WR, Emori TG. CDC definitions of nosocomial surgical site infections, 1992: a modification of CDC definitions of surgical wound infections. Infect Control Hosp Epidemiol. 1992;13 (10):606-8.

2. American College of Obstetricians and Gynecologists, "Practice bulletin No. 104.", Antibiotic Prophylaxis for Gynecologic Procedures, 2009. Obstetrics \& Gynecology. 2009;113(5):1180-1189.

3. Lake AG, McPencow AM, Dick-Biascoechea MA, Martin DK, Erekson EA. Surgical site infection after hysterectomy. Am J Obstet Gynecol. 2013;209(5):490.e1-9. doi: 10.1016/ j.ajog.2013.06.018.

4. Hodges KR, Davis BR, Swaim LS. Prevention and management of hysterectomy complications. Clin Obstet Gynecol. 2014;57 ( 1 ): $43-57 . \quad$ d o i : $10.1097 /$ GRF.0000000000000004. Review.

5. Lachiewicz MP, Moulton LJ, Jaiyeoba O. Infection prevention and evaluation of fever after laparoscopic hysterectomy. JSLS. 2015;19 (3). doi:10.4293/JSLS.2015.00065. Review.

6. Matthews KJ, Brock E, Cohen SA, Chelmow D. Hysterectomy in obese patients: special considerations. Clin Obstet Gynecol. 2014;57 ( 1 ) : $106-14$. doi:10.1097/GR F. 0000000000000005 . Review.
7. Mangram AJ, Horan TC, Pearson ML, Silver LC, Jarvis WR. Guideline for Prevention of Surgical Site Infection, 1999. Centers for Disease Control and Prevention (CDC) Hospital Infection Control Practices Advisory Committee. Am J Infect Control. 1999;27(2):97132.

8. Najjar PA, Smink DS. Prophylactic antibiotics and prevention of surgical site infections. Surg Clin North Am. 2015;95(2):269-83. doi: 10.1016/j.suc.2014.11.006.

9. Kore S, Vyavaharkar M, Akolekar R, Toke A, Ambive V. Comparison of closure of subcutaneous tissue versus non-closure in relation to wound disruption after abdominal hysterectomy in obese patients. J Postgrad Med. 2000;46:26-8.

10. Allaire AD, Fisch J, McMahon MJ. Subcutaneous drain versus suture in obese women undergoing cesarean delivery, a prospective, randomized trial. J Reprod Med. 2000;45:327-31.

11. Ramsey PS, White AM, Guinn DA, Lu GC, Ramin SM, Davies JK, et al. Subcutaneous tissue reapproximation, alone or in combination with drain, in obese women undergoing cesarean delivery. Obstet Gynecol. 2005;105(5 Pt 1):96773.

12. Hellums EK, Lin MG, Ramsey PS. Prophylactic subcutaneous drainage for prevention of wound complications after cesarean delivery--a metaanalysis. Am J Obstet Gynecol. 2007;197 (3):229-35.

13. Inotsume-Kojima $Y$, Uchida $T$, Abe M, Doi $T$, Kanayama N. A combination of subcuticular sutures and a drain for skin closure reduces wound complications in obese women undergoing surgery using vertical incisions. J Hosp Infect. 2011;77(2):162-5. doi: 10.1016/ j.jhin.2010.07.016.

14. Ahmed F. Infectious complications following abdominal hysterectomy in Karachi, Pakistan. Int J Gynecol Obstet. 2000;73:27-34.

15. Walsh C, Scaife C, Hopf H. Prevention and management of surgical site infections in morbidly obese women. Obstet Gynecol. 2009;113:411-5.

16. Morgan-Ortiz F, Soto-Pineda JM, López-Zepeda MA, Peraza-Garay Fde J. Effect of body mass index on clinical outcomes of patients 
undergoing total laparoscopic hysterectomy. Int J Gynaecol Obstet. 2013;120(1):61-4. doi: 10.1016/j.ijgo.2012.08.012.

17. Hourigan JS. Impact of obesity on surgical site infection in colon and rectal surgery. Clin Colon Rectal Surg. 2011;24(4):283-90. doi:10.1055/s0031-1295691.

18. Eddib A, Danakas A, Hughes S, Erk M, Michalik C, Narayanan MS, et al. Influence of Morbid Obesity on Surgical Outcomes in Robotic-Assisted Gynecologic Surgery. J Gynecol Surg. 2014;30(2):81-86.

19. Mahdi H, Gojayev A, Buechel M, Knight J, SanMarco J, Lockhart D, Michener C, MoslemiKebria M. Surgical site infection in women undergoing surgery for gynecologic cancer. Int J Gynecol Cancer. 2014;24(4):779-86. doi:10.1097/IGC.0000000000000126.

20. Savage MW, Pottinger JM, Chiang HY, Yohnke KR, Bowdler NC, Herwaldt LA. Surgical site infections and cellulitis after abdominal hysterectomy. Am J Obstet Gynecol. 2013;209 (2):108.e1-10. doi: 10.1016/j.ajog.2013.05.043.

21. Martin ET, Kaye KS, Knott C, Nguyen H, Santarossa M, Evans R, Bertran E, Jaber L. Diabetes and Risk of Surgical Site Infection: A
Systematic Review and Meta-analysis. Infect Control Hosp Epidemiol. 2016;37(1):88-99. doi: 10.1017/ice.2015.249.

22. Krieger Y, Walfisch A, Sheiner E. Surgical site infection following cesarean deliveries: trends and risk factors. J Matern Fetal Neonatal Med. 2017;30(1):8-12.

23. Kadija S, Stefanovic A, Jeremic K, Tavcar J, Argirovic R, Pantovic S. Malignant disease as a risk factor for surgical site infection. Clin Exp Obstet Gynecol. 2012;39:53-6.

24. Korol E, Korol E, Johnston K, Waser N, Sifakis F, Jafri HS, Lo M, Kyaw MH. A systematic review of risk factors associated with surgical site infections among surgical patients. PLoS One. 2013;8(12):e83743. doi: 10.1371/ journal.pone.0083743. eCollection 2013.

25. Perencevich EN, Sands KE, Cosgrove SE, Guadagnoli E, Meara E, Platt R. Health and economic impact of surgical site infections diagnosed after hospital discharge. Emerg Infect Dis. 2003;9(2):196-203. 
Tablo 1. Olguların operasyon bilgileri.

\begin{tabular}{|c|c|c|}
\hline & Sayı $(n=117)$ & Yüzde \\
\hline \multicolumn{3}{|l|}{ Preoperatif transfüzyon } \\
\hline Yap1ld1 & 10 & 8,5 \\
\hline Yapılmadi & 107 & 91,5 \\
\hline \multicolumn{3}{|l|}{ Operasyon } \\
\hline Sezeryan & 37 & 31,6 \\
\hline TAH BSO & 38 & 32,5 \\
\hline Myomektomi & 15 & 12,8 \\
\hline Jinekolojik kanser & 16 & 13,7 \\
\hline Kistektomi & 5 & 4,3 \\
\hline $\mathrm{VAH}$ & 6 & 5,1 \\
\hline \multicolumn{3}{|l|}{ İnsizyon } \\
\hline Phannenstiel & 86 & 73,5 \\
\hline GAM & 7 & 6,0 \\
\hline GAM-GÜM & 18 & 15,4 \\
\hline Vajinal & 6 & 5,1 \\
\hline \multicolumn{3}{|l|}{ İntraabdominal dren } \\
\hline Var & 66 & 56,4 \\
\hline Yok & 51 & 43,6 \\
\hline \multicolumn{3}{|l|}{ Hospitalizasyon süresi } \\
\hline 1-2 gün & 55 & 47,0 \\
\hline 2-14 gün & 47 & 40,2 \\
\hline 15-28 gün & 12 & 10,3 \\
\hline 29 gün ve üzeri & 3 & 2,6 \\
\hline
\end{tabular}

TAH: total abdominal histerektomi; BSO: bilateral salpingooferektomi; VAH: vajinal histerektomi; GAM: göbekaltı medyan insizyon; GÜM: göbeküstü medyan insizyon; LS: laparoskopi 
Tablo 2. Cerrahi alan enfeksiyonu gelişen olgulara ait bilgiler.

\begin{tabular}{|l|c|c|}
\hline Özellikler & Sayı (n=65) & Yüzde \\
\hline Enfeksiyonun ortaya çıma zamanı & 32 & 49.2 \\
1.hafta & 28 & 43,1 \\
2. hafta & 4 & 6,2 \\
3.hafta & 1 & 1,5 \\
4. hafta & & \\
\hline Kültürde üreme & 19 & 29,2 \\
Var & 46 & 70,8 \\
Yok & 14 & 21,5 \\
\hline Nekroz & 51 & 78,5 \\
Var & & \\
Yok & 4 & 6,2 \\
\hline Hematom & 61 & 93,8 \\
Var & & \\
Yok & 57 & 87,7 \\
\hline Sekonder sütur & 8 & 12,3 \\
Var & & \\
Yok & 61 & 93,8 \\
\hline Fasya defekti & & \\
Var & & \\
Yok & & \\
\hline
\end{tabular}

Anket Formu 
Tablo 3. Olguların demografik ve komorbidite açısından karşılaştırılması.

\begin{tabular}{|c|c|c|c|c|c|c|}
\hline & \multicolumn{2}{|c|}{$\begin{array}{c}\text { Yara yeri enfeksiyonu } \\
\operatorname{var}(n=65)\end{array}$} & \multicolumn{2}{|c|}{$\begin{array}{c}\text { Yara yeri enfeksiyo- } \\
\text { nu yok }(n=62)\end{array}$} & \multirow[b]{2}{*}{$\chi^{2 / t}$} & \multirow[b]{2}{*}{$\mathbf{p}$} \\
\hline & Sayı & Yüzde & Sayı & Yüzde & & \\
\hline \multicolumn{7}{|l|}{ Diyabet } \\
\hline Var & 25 & 75,8 & 8 & 24,2 & 7,597 & 0,006 \\
\hline Yok & 40 & 47,6 & 44 & 52,4 & & \\
\hline \multicolumn{7}{|l|}{ Hipertansiyon } \\
\hline Var & 33 & 70,2 & 14 & 29,8 & 6,835 & 0,009 \\
\hline Yok & 32 & 45,7 & 38 & 54,3 & & \\
\hline \multicolumn{7}{|l|}{ Malignite } \\
\hline Var & 12 & 80,0 & 3 & 20,0 & 4,164 & 0,041 \\
\hline Yok & 53 & 52,0 & 49 & 48,0 & & \\
\hline \multicolumn{7}{|l|}{ Dren } \\
\hline Var & 37 & 56,1 & 29 & 43,9 & 0,016 & 0,900 \\
\hline Yok & 28 & 54,9 & 23 & 45,1 & & \\
\hline \multicolumn{7}{|l|}{ Var } \\
\hline \multirow[t]{2}{*}{ Yok } & 7 & 70,0 & 3 & 30,0 & 0,924 & $0,509 *$ \\
\hline & 58 & 54,2 & 49 & 45,8 & & \\
\hline \multicolumn{7}{|l|}{ Sigara } \\
\hline İçiyor & 54 & 55,1 & 44 & 44,9 & 0,050 & 0,823 \\
\hline İçmiyor & 11 & 57,9 & 8 & 42,1 & & \\
\hline BKI*** & \multicolumn{2}{|c|}{$31,40 \pm 6,25$} & \multicolumn{2}{|c|}{$25,98 \pm 2,79$} & 6,256 & $<0,001$ \\
\hline Vücut ağırlığı & \multicolumn{2}{|c|}{$81,11 \pm 16,96$} & \multicolumn{2}{|c|}{$67,62 \pm 7,44$} & 5,759 & $<0,001$ \\
\hline Yaş & \multicolumn{2}{|c|}{$48,00 \pm 612,52$} & \multicolumn{2}{|c|}{$40,73 \pm 6,25$} & 3,052 & 0,003 \\
\hline
\end{tabular}

*Fisher's Exact Test

**BKI: beden kitle indeksi 